\title{
Sea Surface Temperatures: Seasonal Persistence and Trends
}

\author{
LUIS A. GIL-ALANA ${ }^{\mathrm{a}}$ \\ Faculty of Economics, and Institute for Culture and Society, University of Navarra, Pamplona, Spain \\ Manuel Monge And María FÁtima Romero Rojo \\ Universidad Francisco de Vitoria, Madrid, Spain
}

(Manuscript received 6 June 2019, in final form 8 August 2019)

\begin{abstract}
This paper addresses analysis of the global monthly sea surface temperatures using a reconstructed dataset that goes back to 1884 . We use fractional integration methods to examine features such as persistence, seasonality, and time trends in the data. The results show that seasonality is a relevant issue, finding evidence of seasonal unit roots. With the seasonal component removed, persistence is also very significant, and, when looking at the data month by month, evidence of significant linear trends is detected in all cases. According to these results, monthly sea surface temperatures increase by between $0.07^{\circ}$ and $0.11^{\circ} \mathrm{C}$ every 100 years .
\end{abstract}

\section{Introduction}

The interest in global warming and climate change has increased rapidly in recent years. There is agreement that Earth's surface temperature has increased over the last 100 years by between $\sim 0.3^{\circ}$ and $\sim 0.6^{\circ} \mathrm{C}$. (IPCC 1995 ; Cane et al. 1997; Hansen and Lebedeff 1988; Nicholls et al. 1996; Jones and Wigley 2010; Folland et al. 2018; etc.). The causes of this temperature increase may be a response to anthropogenic forcing (industrialization and the effect of burning and emissions of fossil fuel, increases in the greenhouse gas concentration that affect the atmosphere, etc.), a part of the climate system's innate natural variability (e.g., solar irradiance), or a combination of the two. However, most of the scientific community maintains an almost unanimous agreement on this topic supporting the anthropogenic origin of climate change (Anderegg et al. 2010; Beckage et al. 2018).

The surface air temperature is considered as the usual variable to determine climate change, and many articles have investigated the presence of time trends in air temperatures either at a global level (Santer et al. 1995; Hegerl et al. 1996, 1997; Jones and Hegerl 1998; Hansen et al. 2010; Rajaratnam et al. 2015; Poppick et al.

\footnotetext{
a Additional affiliation: Universidad Francisco de Vitoria, Madrid Spain.
}

Corresponding author: Luis A. Gil-Alana, alana@unav.es
2017; etc.) or at a local and regional temperatures (Ghil and Vautard 1991; Hasselmann 1993; Schlesinger and Ramankutty 1994; North and Kim 1995; North et al. 1995; Papalexiou et al. 2018; King et al. 2018; etc.). However, sea surface temperature (SST) is a fundamental physical parameter for the understanding of climate dynamics and climate change because of the oceans' large thermal inertia as compared with that of the atmosphere and land (Deser et al. 2010).

In this research we focus on understanding sea surface temperatures and their behavior with a monthly time frequency. This paper is a contribution to the literature on the analysis of sea surface temperature from a time series viewpoint focusing on features such as seasonality, time trends, and persistence. To this purpose, we examine the time series properties of the global monthly sea surface temperatures from January 1884 to January 2019. Another contribution of this work is that by the first time we jointly examined the three features (time trends, persistence and seasonality) in a unified treatment based on long memory and fractional integration, which has not been jointly studied so far in SST data. The dataset was obtained from the KNMI Climate Explorer, which is a web application to analysis climate data statistically. This tool is made available by the World Meteorological Organization along with the European Climate Assessment and Data.

The rest of the paper is organized as follows: In section 2 we briefly review the literature on sea surface 


\section{Sea surface temperature}

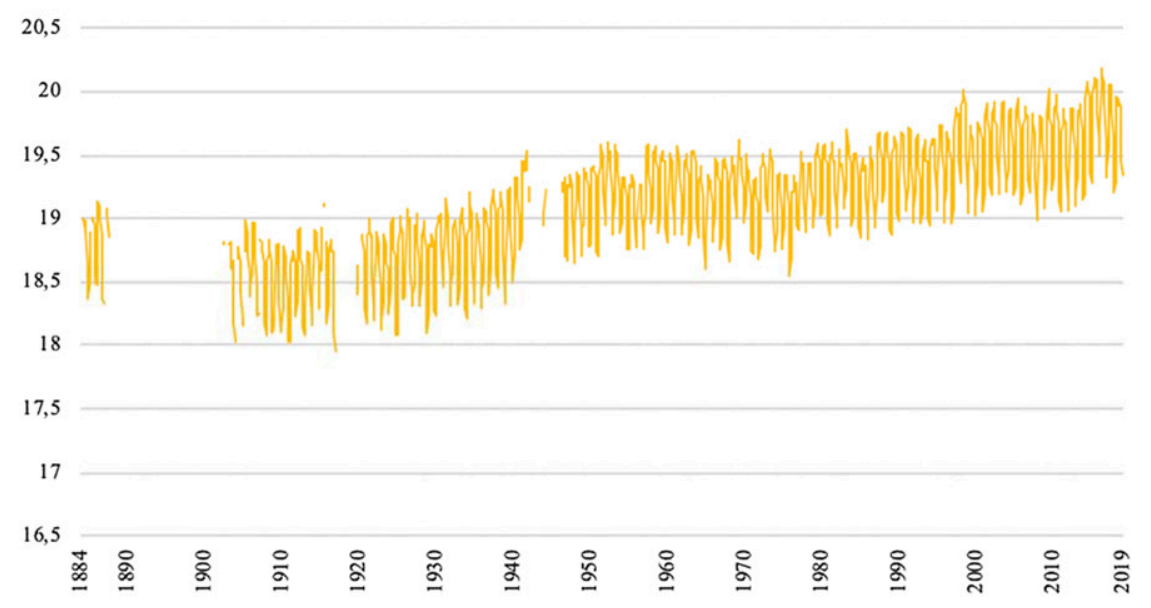

FIG. 1. Times series plot of the original sea surface temperature data obtained from KNMI. The monthly time period analyzed is from January 1884 to January 2019.

temperatures. In section 3 we present the techniques used in the paper. Section 4 describes the dataset. Section 5 contains the empirical results. Section 6 concludes the paper.

\section{Sea surface temperatures}

Temperatures of the sea surface are used as a key factor connecting the oceans to the global climate system. An example of this affirmation is collected in the research done by Yaya and Akintande (2018) that relates global and regional sea surface and land air surface temperatures finding evidence of a high correlation between them. Also, SST anomalies in the tropical Pacific are commonly used indicators for diagnosing the El Niño-Southern Oscillation (ENSO) state, and the impact of global warming on SST-based ENSO monitoring indices have been analyzed recently (Turkington et al. 2019).

SST might present certain irregularities and its potential nonlinear pattern creates difficulties to measure it. Nevertheless, reliable data can be found at the Hadley Centre (Rayner et al. 2003, 2006, 2009; Minobe and Maeda 2005; etc.), and also at the National Oceanic and Atmospheric Administration (Smith et al. 2008) and in Kaplan et al. (1998), among other sources.

One of the main assumptions regarding the classical definition of temperature anomalies is that the annual cycle is constant and does not change over time. To analyze the SST anomalies, several statistical methods have been used, such as optimal smoothing, the Kalman filter, and optimal interpolation (Kaplan et al. 1998). However, more accurate data, achieved by including bias-adjusted satellite data, and accurate analysis are required to minimize errors (Smith et al. 2008; Banzon et al. 2016).

On the other hand, several authors have claimed that the climate system presents memory or persistence across different regimes. In 2003, Gil-Alana introduced fractional integration techniques to analyze the central England temperature from 1659 to 2001, which is the longest available instrumental record of temperature in the world. The results show that central England temperatures have increased by approximately $0.23^{\circ} \mathrm{C}$ $(100 \mathrm{yr})^{-1}$ in recent history (Gil-Alana 2003). Also, he evaluated the warming in both the Northern and Southern Hemispheres (Gil-Alana 2005). Other authors that have also found persistence and evidence of long memory in temperatures and sea temperatures are Eichner et al. (2003), Lennartz and Bunde (2009), Franzke (2012a, 2013), Bunde et al. (2014), Ludescher et al. (2016), Massah and Kantz (2016), Yaya and Akintande (2018), and Deng et al. (2018), among many others. On the other hand, ÁlvarezRamirez et al. (2008) showed that ocean temperatures are more persistent than land temperatures and several authors have studied recently the SST locally, in different areas, for instance, in the Mediterranean Sea (Shaltout and Omstedt 2014), Baltic Sea (Stramska and Białogrodzka 2015), and southwest coast of Portugal (Goela et al. 2016), pointing at a general increasing of the local temperature, hence contributing to global warming (Mudelsee 2019). Interestingly, Breaker (2019) has recently estimated long-range persistence in the ocean surface temperature of the coast of central California, a region where similar observations had not been made. Other papers that analyze time structure 
(a) Sea Surface Temperatures $1947-2019$

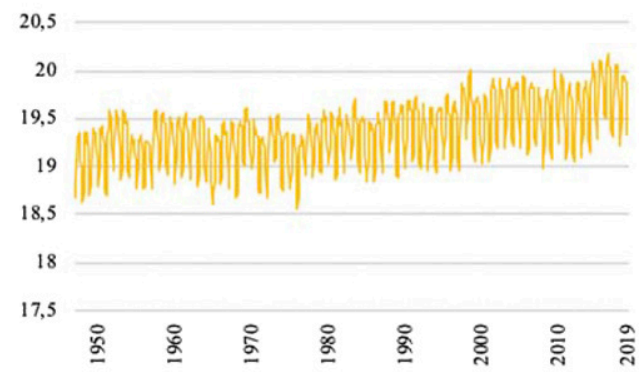

(c) Sea Surface Temperatures $1904-2019$

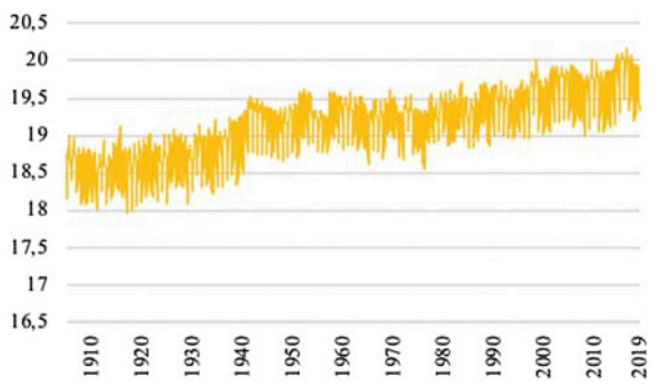

(b) Sea Surface Temperatures $1922-2019$

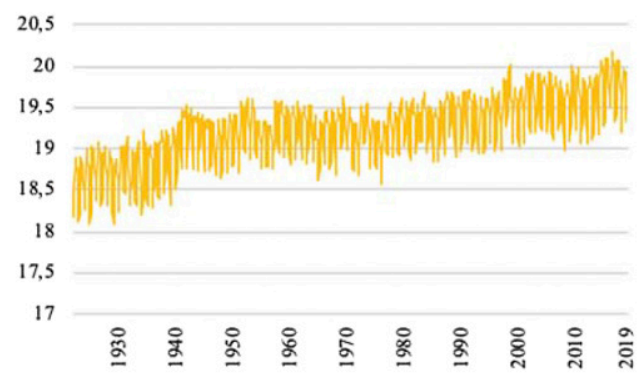

(d) Sea Surface Temperatures $1884-2019$

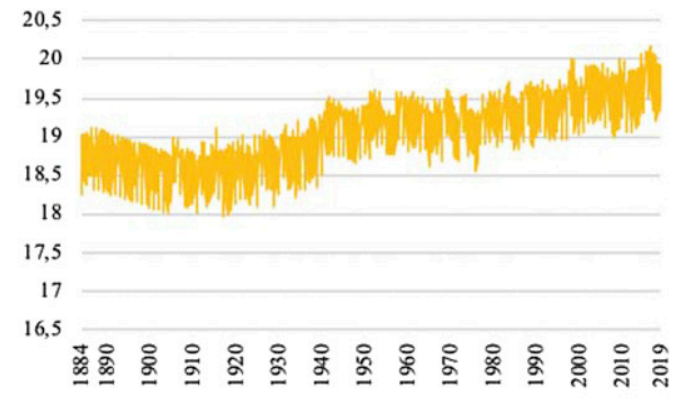

FIG. 2. Time series plots of sea surface temperatures for different time periods.

dependencies and dynamics in temperatures are Stern and Kaufmann (2000), Kaufmann and Stern (2002), Jones and Moberg (2003), Gil-Alana (2003, 2005), Moberg et al. (2005), Mills (2004, 2006, 2007), GilAlana (2008b, 2015), Deng et al. (2018) and Yaya and Akintande (2018).

\section{Method}

Because the main goal in the paper is to show whether there is a linear trend in the sea surface temperatures across the years, our initial model is based on the following regression:

$$
y_{t}=\alpha+\beta t+x_{t} ; \quad t=1,2, \ldots,
$$

where $y_{t}$ refers to the observed data, that is, the anomalies over sea surface temperatures; $\alpha$ and $\beta$ are unknown coefficients that refer, respectively, to a constant and a potential linear trend in time; and $x_{t}$ is the error term (or the detrended series) that is supposed to be well behaved. Thus, for example, if this error term in Eq. (1) is a random variable independently and normally distributed with mean zero and a constant variance, the ordinary least squares (OLS) estimate of $\beta$ can be obtained, and statistical inference based on the classical $F$ and $t$ statistics can be applied here
(Hamilton 1994). Thus, if we are able to reject the null hypothesis of

$$
H_{0}=\beta=0
$$

versus the alternative,

$$
H_{a}=\beta>0,
$$

we can then claim that temperatures are increasing over time. Nevertheless, a pattern that is observed in monthly sea surface temperatures is that they display several features that are not consistent with standard models, for example, seasonality, along with strong dependence between the observations across time.

Following Hylleberg $(1986,1992)$ seasonality can be defined as a systematic, although not necessarily regular, variation around trend in time series. This author classifies seasonality in three categories when modeling seasonal data: 1) purely deterministic models (by means of seasonal dummy variables), 2) seasonal stochastic stationary models [using seasonal autoregressive moving-average (ARMA) processes], and 3) seasonal nonstationarity (by means of seasonal differences). The first group based on seasonal dummies simply allows for the mean of the series to vary by season, and therefore it raises no statistically 
TABLE 1. Estimated coefficients in the model given by Eq. (8), with no autocorrelation. The values in parentheses in the intercept column are $t$ values. Thus, values above 1.645 in absolute value indicate statistical significance at the $5 \%$ level.

\begin{tabular}{ccccc}
\hline \hline Series & $d(95 \%$ band $)$ & Intercept & $\begin{array}{c}\text { Time } \\
\text { trend }\end{array}$ & $\begin{array}{c}\text { Seasonal } \\
\text { coef }\end{array}$ \\
\hline $1884-2018$ & $0.74(0.69,0.78)$ & $18.366(107.19)$ & - & 0.917 \\
$1904-2018$ & $0.75(0.70,0.80)$ & $18.368(110.40)$ & - & 0.916 \\
$1922-2018$ & $0.81(0.76,0.86)$ & $18.275(109.89)$ & - & 0.922 \\
$1947-2018$ & $0.86(0.81,0.92)$ & $18.765(116.07)$ & - & 0.923 \\
\hline
\end{tabular}

interesting issues. In the empirical application carried out below we use stochastic approaches using first a simple autoregressive of order 1 [AR(1)] process of the form

$$
u_{t}=\varphi u_{t-12}+\varepsilon_{t}, \quad t=1,2, \ldots,
$$

assuming so far that $x_{t}=u_{t}$, and where $\varepsilon_{t}$ is a white noise process. Thus, $\varphi$ indicates the degree of seasonal serial dependence. ${ }^{1}$ If nonseasonal dependence is also permitted, we can add the following model:

$$
(1-L)^{d} x_{t}=u_{t}, \quad t=0, \pm 1, \ldots,
$$

with $x_{t}=u_{t}=0$ for $t \leq 0$, where $L$ indicates the lag operator, that is, $L^{k} x_{t}=x_{t-k}$, and $d$ can be any real value. Clearly, if $d=0, x_{t}=u_{t}$, there is no dependence at all, and the classical estimation of $\beta$ in Eq. (1) and based on OLS or generalized least squares still remains valid. However, allowing for $d>0$, dependence is permitted, and the higher the value of $d$ is, the higher the level of dependence between the observations is, noting that the polynomial on the left-hand side of Eq. (5) can be expressed, for all real $d$, as

$$
\begin{aligned}
(1-L)^{d} & =\sum_{j=0}^{\infty} \psi_{j} L^{j}=\sum_{j=0}^{\infty}\left(\begin{array}{l}
d \\
j
\end{array}\right)(-1)^{j} L^{j} \\
& =1-d L+\frac{d(d-1)}{2} L^{2}-\cdots,
\end{aligned}
$$

and thus Eq. (5) can be expressed as

$$
(1-L)^{d} x_{t}=x_{t}-d x_{t-1}+\frac{d(d-1)}{2} x_{t-2}-\cdots+u_{t} .
$$

Then it is said that $x_{t}$ is integrated of order $d$ and denoted as $I(d)$. This type of process displays the property of long memory because of the strong degree of association between observations that are far distant in time. They were introduced in the earlier 1980s by Granger (1980,

\footnotetext{
${ }^{1}$ In the empirical application carried out in section 5 , the seasonal AR parameter is found to be very close to 1 , suggesting the need for seasonal differentiation. In fact, after performing seasonal unit root tests, the results support this hypothesis in all series.
}

TABLE 2. Estimated values of $d$ on the first seasonal differences. The values in parenthese indicate the $95 \%$ confidence band for the values of $d$; boldface font indicates the selected model for each series.

\begin{tabular}{cccc}
\hline \hline Series & No terms & With intercept & With time trend \\
\hline \multicolumn{4}{c}{ With no autocorrelation } \\
$1884-2018$ & $0.73(0.69,0.77)$ & $\mathbf{0 . 7 3}(\mathbf{0 . 6 9}, \mathbf{0 . 7 7})$ & $0.73(0.69,0.77)$ \\
$1904-2018$ & $0.74(0.70,0.79)$ & $\mathbf{0 . 7 5}(\mathbf{0 . 7 0 , 0 . 7 9 )}$ & $0.75(0.70,0.79)$ \\
$1922-2018$ & $\mathbf{0 . 7 9}(\mathbf{0 . 7 5 , 0 . 8 3 )}$ & $0.79(0.75,0.84)$ & $0.80(0.75,0.84)$ \\
$1947-2018$ & $\mathbf{0 . 8 5}(\mathbf{0 . 8 0 , 0 . 9 1 )}$ & $0.86(0.81,0.91)$ & $0.86(0.81,0.91)$ \\
\multicolumn{4}{c}{ With autocorrelation } \\
$1884-2018$ & $0.82(0.69,0.90)$ & $\mathbf{0 . 8 1}(\mathbf{0 . 7 1 , 0 . 8 9 )}$ & $0.81(0.71,0.89)$ \\
$1904-2018$ & $0.79(0.69,0.91)$ & $\mathbf{0 . 8 0}(\mathbf{0 . 7 0 , 0 . 9 0 )}$ & $0.80(0.70,0.90)$ \\
$1922-2018$ & $\mathbf{0 . 8 6}(\mathbf{0 . 7 5}, \mathbf{0 . 9 9})$ & $0.85(0.76,1.00)$ & $0.85(0.76,1-00)$ \\
$1947-2018$ & $\mathbf{0 . 9 9 ( 0 . 8 7 , 1 . 1 5 )}$ & $1.02(0.86,1.16)$ & $1.02(0.86,1.16)$ \\
\hline
\end{tabular}

1981), Granger and Joyeux (1980) and Hosking (1981) and since then have been widely employed in the analysis of aggregate data including climatological and meteorological data (Bloomfield 1992; Koscielny-Bunde et al. 1998; Percival et al. 2001; Monetti et al. 2003; GilAlana 2005, 2008a, 2015, 2018; Rybski et al. 2006, 2008; Fatichi et al. 2009; Franzke 2010, 2012b; Bunde et al. 2014; Yuan et al. 2015; Ludescher et al. 2016; Bunde 2017; GilAlana et al. 2019; Gil-Alana and Sauci 2019; among many others). In this context of fractional integration, the estimation of $\beta$ in Eq. (1) must take into account the additional dependence structure on the error term.

We estimate the model by using the Whittle function in the frequency domain (Dahlhaus 1989). The Whittle function is an approximation to the likelihood function, and we use this function in the context of a testing procedure developed in Robinson (1994) that is very convenient with our dataset. This method allows us to test the null hypothesis

$$
H_{0}=d=d_{0},
$$

for any real value $d_{0}$, in a model given by Eqs. (1) and (5) independent of the specification of $u_{t}$ in Eq. (5), which may be a seasonal AR(1) process as in Eq. (4). The test statistic has a standard null $N(0,1)$ limit distribution and is the most efficient method in the Pitman sense against local departures from the null. Moreover, this standard behavior holds for any value of $d_{0}$, including thus stationary $\left(d_{0}<0.5\right)$ and nonstationary $\left(d_{0} \geq 0.5\right)$ hypotheses.

\section{Data}

The data examined in this work are the anomalies over the global monthly sea surface temperatures and have been obtained from the KNMI Climate Explorer (https://climexp.knmi.nl/select.cgi?id=someone@ somewhere\&field=coads_sst), which is part of the World 
TABLE 3. Seasonal persistence and trends with sample size: 1884-2018. The values in parentheses in the second and fourth columns indicate the $95 \%$ confidence band for the values of $d$; those reported in the third and fifth columns are $t$ values.

\begin{tabular}{|c|c|c|c|c|}
\hline \multirow{2}{*}{$\frac{\text { Month }}{\text { Jan }}$} & \multicolumn{2}{|c|}{ No autocorrelation } & \multicolumn{2}{|c|}{ With autocorrelation } \\
\hline & $0.55(0.45,0.67)$ & $0.0078(5.20)$ & $0.54(0.37,0.74)$ & $0.0078(5.14)$ \\
\hline Feb & $0.63(0.52,0.77)$ & $0.0071(3.38)$ & $0.54(0.36,0.78)$ & $0.0071(4.57)$ \\
\hline Mar & $0.58(0.46,0.73)$ & $0.0085(5.25)$ & $0.43(0.25,0.66)$ & $0.0086(8.01)$ \\
\hline Apr & $0.55(0.46,0.68)$ & $0.0084(6.36)$ & $0.53(0.36,0.76)$ & $0.0084(6.34)$ \\
\hline May & $0.63(0.54,0.76)$ & $0.0073(4.41)$ & $0.62(0.48,0.79)$ & $0.0073(4.46)$ \\
\hline Jun & $0.60(0.50,0.76)$ & $0.0076(5.30)$ & $0.52(0.36,0.69)$ & $0.0077(6.78)$ \\
\hline Jul & $0.58(0.48,0.71)$ & $0.0077(5.47)$ & $0.54(0.38,0.70)$ & $0.0078(6.01)$ \\
\hline Aug & $0.61(0.52,0.75)$ & $0.0075(4.91)$ & $0.54(0.38,0.71)$ & $0.0076(6.16)$ \\
\hline Sep & $0.62(0.52,0.75)$ & $0.0076(5.07)$ & $0.65(0.45,0.85)$ & $0.0075(4.34)$ \\
\hline Oct & $0.66(0.55,0.80)$ & $0.0075(3.73)$ & $0.58(0.36,0.80)$ & $0.0077(5.00)$ \\
\hline Nov & $0.56(0.46,0.67)$ & $0.0077(4.92)$ & $0.63(0.44,0.87)$ & $0.0077(3.65)$ \\
\hline Dec & $0.44(0.36,0.55)$ & $0.0082(7.70)$ & $0.63(0.44,0.80)$ & $0.0077(3.57)$ \\
\hline
\end{tabular}

Meteorological Organization, and from the European Climate Assessment and Data. The monthly time period examined stretches from January 1884 to January 2019.

Figure 1 plots the original data of the sea surface temperature time series obtained from KNMI. As can be observed, there are periods of time during which the information is incomplete. For this reason, first we have analyzed the time periods where we have complete data (see Fig. 2a), with data starting in 1947. Then we have also linearized the time series with the purpose of being able to analyze periods of longer duration in the data, starting in 1922 (Fig. 2b), 1904 (Fig. 2c), and 1884 (Fig. 2d). ${ }^{2}$

\section{Results}

On the basis of the monthly nature of the data, we start by using the model given by Eqs. (1), (4), and (5), that is,

$$
y_{t}=\alpha+\beta t+x_{t}, \quad(1-L)^{d} x_{t}=u_{t}, \quad\left(1-\varphi L^{12}\right) x_{t}=\varepsilon_{t},
$$

testing the $H_{0}$ in Eq. (6) for $d_{0}$ values equal to $0,0.01$, $0.02, \ldots, 1.99$, and 2. As earlier mentioned, this parameter is very relevant in the sense that it is informing us about the degree of dependence in the data and thus can be taken as an indicator of the level of persistence. The higher the differencing parameter is, the higher the level of persistence is.

We conduct the estimation of $d_{0}$ under three different setups: 1) with no deterministic terms, that is, assuming that $\alpha=\beta=0$ in Eq. (7), 2) with an intercept, that is, imposing $\beta=0$, and 3 ) with an intercept and a linear time trend, that is, estimating $\alpha$ and $\beta$ along with the other parameters in the model. We selected the appropriate

\footnotetext{
${ }^{2}$ All reconstructions are based on linear extrapolation using the last observation prior to the break and the first one after the break.
}

models by using their corresponding $t$ values, and the results showed that the time trend is not required in any of the four series, the intercept being sufficient to describe the deterministic components. The results of the estimated coefficients are reported in Table 1 . The estimated values of $d$ are 0.73 for the sample starting in 1884, 0.74 for the one starting in 1904, and slightly higher (0.81 and 0.86 ) for those starting in 1922 and 1947. If we look at the confidence intervals, we see that all values belong to the interval $[0.5,1)$, implying nonstationary mean reverting behavior. However, if we focus on the seasonal AR coefficients, we see that they are all very close to 1 , suggesting that the series may contain seasonal unit roots.

On the basis of these high seasonal AR coefficients, we next conducted seasonal unit root tests that are based on the methods of Dickey et al. (1984), Beaulieu and Miron (1993), and Hylleberg et al. (1990), and the results, although not reported, suggested evidence of unit roots in the four series. ${ }^{3}$ Thus, we perform seasonal first differences, and work next with the differenced series. Here, noting that seasonality has been removed, we consider the model given only by Eqs. (1) and (4), that is,

$y_{t}=\alpha+\beta t+x_{t}, \quad(1-L)^{d} x_{t}=u_{t}, \quad t=1,2, \ldots$,

under the assumptions that $u_{t}$ is both white noise, that is, $u_{t}=\varepsilon_{t}$, and autocorrelated. However, in the latter case, instead of imposing a particular parametric (ARMA) structure on $u_{t}$, we use a nonparametric approach that is due to Bloomfield (1973) and that approximates ARMA models with very few parameters. ${ }^{4}$

\footnotetext{
${ }^{3}$ The same evidence in favor of seasonal unit roots was obtained when using seasonal fractionally integrated methods (see Gil-Alana and Robinson 2001).

${ }^{4}$ Nonlinear deterministic terms of the form advocated by Cuestas and Gil-Alana (2016) were also employed, but the coefficients were found to be statistically insignificant in all cases.
} 
TABLE 4. Seasonal persistence and trends with sample size: 1904-2018. The values in parentheses in the second and fourth columns indicate the $95 \%$ confidence band for the values of $d$; those reported in the third and fifth columns are $t$ values.

\begin{tabular}{|c|c|c|c|c|}
\hline \multirow{2}{*}{$\frac{\text { Month }}{\text { Jan }}$} & \multicolumn{2}{|c|}{ No autocorrelation } & \multicolumn{2}{|c|}{ With autocorrelation } \\
\hline & $0.46(0.35,0.1)$ & $0.0100(7.44)$ & $0.43(0.25,0.68)$ & $0.0101(7.17)$ \\
\hline Feb & $0.49(0.34,0.73)$ & $0.0084(5.28)$ & $0.31(0.12,0.72)$ & $0.0092(8.91)$ \\
\hline Mar & $0.52(0.40,0.70)$ & $0.0100(6.29)$ & $0.37(0.19,0.62)$ & $0.0101(8.63)$ \\
\hline Apr & $0.42(0.31,0.57)$ & $0.0104(9.99)$ & $0.35(0.18,0.61)$ & $0.0104(9.55)$ \\
\hline May & $0.50(0.37,0.68)$ & $0.0103(8.49)$ & $0.33(0.14,0.57)$ & $0.0105(11.28)$ \\
\hline Jun & $0.43(0.30,0.63)$ & $0.0103(10.66)$ & $0.24(0.07,0.44)$ & $0.0105(13.67)$ \\
\hline Jul & $0.43(0.31,0.62)$ & $0.0100(9.65)$ & $0.32(0.15,0.63)$ & $0.0102(10.82)$ \\
\hline Aug & $0.47(0.35,0.66)$ & $0.0103(9.23)$ & $0.30(0.15,0.51)$ & $0.0105(12.05)$ \\
\hline Sep & $0.50(0.38,0.68)$ & $0.0105(8.97)$ & $0.41(0.24,0.71)$ & $0.0105(9.68)$ \\
\hline Oct & $0.56(0.42,0.74)$ & $0.0106(6.25)$ & $0.39(0.21,0.64)$ & $0.0106(9.16)$ \\
\hline Nov & $0.47(0.36,0.62)$ & $0.0106(7.61)$ & $0.47(0.28,0.79)$ & $0.0106(6.77)$ \\
\hline Dec & $0.30(0.21,0.43)$ & $0.0107(12.66)$ & $0.40(0.22,0.66)$ & $0.0106(7.55)$ \\
\hline
\end{tabular}

The top half of Table 2 displays the estimates under the assumption of white noise errors, whereas the bottom half focuses on the case of autocorrelation. The values are very similar in the two cases, and the first thing we observe is that the time trend is not required in any single case. The estimates of $d$ are large, though smaller than 1 in all cases, with the exception of the dataset starting in 1947 with autocorrelated errors. These results indicate that the data are highly persistent but no evidence of time trends is detected on the data.

As a final step in the analysis, we focus on the data separated by months, testing once more the degree of persistence and the significance of the time trend coefficients in the model given by Eq. (8) for the two types of residuals (uncorrelated and following the model of Bloomfield). The results for the reconstructed dataset starting in 1884 are presented in Table 3. The first thing we observe is that all estimated values of $d$ are positive and smaller than 1 implying, once more, fractional integration. The values range between 0.43 (March with autocorrelation) and 0.66 (October with no autocorrelation). However, the most interesting feature is that the time trend coefficients are now statistically significant in all cases, implying an increase in the temperatures during the sample period. Under no autocorrelation, the highest increases take place in March (0.085) and April (0.083), implying an increase of about $0.8^{\circ} \mathrm{C}$ in the temperatures every 100 years, and a very similar result is obtained under autocorrelated errors.

Tables 4, 5 and 6 display the results for the subsamples starting at 1904, 1922 and 1947, respectively. For the first two of these subsamples, the estimated values of $d$ are very similar to those in Table 3 (with values of $d$ ranging from 0.24 to 0.57 ); however, the time trend coefficients are much higher than those in Table 3, with values above 0.010 in practically all cases, implying increases above $0.10^{\circ} \mathrm{C}(100 \mathrm{yr})^{-1}$ for each month of the year. In Table 6 , the results refer to the observed data between 1947 and 2018. Here, the values of $d$ are much smaller than in the previous cases, ranging from 0.12 to 0.46 with no autocorrelation and being much smaller with the model of Bloomfield. In fact, the $I(0)$ hypothesis of short memory (i.e., $d=0$ ) cannot be

TABLE 5. Seasonal persistence and trends with sample size: 1922-2018. The values in parentheses in the second and fourth columns indicate the $95 \%$ confidence band for the values of $d$; those reported in the third and fifth columns are $t$ values.

\begin{tabular}{lllll}
\hline \hline Month & \multicolumn{2}{c}{ No autocorrelation } & \multicolumn{1}{c}{ With autocorrelation } \\
\hline Jan & $0.46(0.35,0.60)$ & $0.0108(6.61)$ & $0.44(0.23,0.70)$ & $0.0107(6.25)$ \\
Feb & $0.47(0.34,0.62)$ & $0.0104(5.94)$ & $0.34(0.12,0.58)$ & $0.0101(7.33)$ \\
Mar & $0.57(0.43,0.76)$ & $0.0107(4.85)$ & $0.31(0.15,0.65)$ & $0.0104(17.66)$ \\
Apr & $0.49(0.36,0.68)$ & $0.0110(7.44)$ & $0.29(0.08,0.59)$ & $0.0115(9.28)$ \\
May & $0.54(0.39,0.75)$ & $0.0117(6.93)$ & $0.17(-0.02,0.42)$ & $0.0109(9.86)$ \\
Jun & $0.46(0.32,0.69)$ & $0.0112(8.69)$ & $0.36(0.14,0.58)$ & $0.0105(12.44)$ \\
Jul & $0.47(0.35,0.65)$ & $0.0109(8.14)$ & $0.31(0.09,0.58)$ & $0.0107(8.97)$ \\
Aug & $0.53(0.40,0.72)$ & $0.0115(7.31)$ & $0.42(0.18,0.73)$ & $0.0109(10.26)$ \\
Sep & $0.51(0.38,0.69)$ & $0.0115(7.67)$ & $0.44(0.17,0.76)$ & $0.0112(8.06)$ \\
Oct & $0.60(0.46,0.80)$ & $0.0118(5.10)$ & $0.57(0.30,0.92)$ & $0.0113(7.12)$ \\
Nov & $0.48(0.36,0.64)$ & $0.0113(6.56)$ & $0.43(0.23,0.69)$ & $0.0116(4.82)$ \\
Dec & $0.29(0.20,0.42)$ & $0.0109(10.64)$ & $0.0113(6.25)$ \\
\hline
\end{tabular}


TABLE 6. Seasonal persistence and trends with sample size: 1947-2018. The values in parentheses in the second and fourth columns indicate the $95 \%$ confidence band for the values of $d$; those reported in the third and fifth columns and are $t$ values.

\begin{tabular}{lllll}
\hline \hline Month & \multicolumn{2}{c}{ No autocorrelation } & \multicolumn{1}{c}{ With autocorrelation } \\
\hline Jan & $0.14(0.00,0.35)$ & $0.0070(7.75)$ & $0.01(-0.25,0.32)$ & $0.0060(8.21)$ \\
Feb & $0.18(0.04,0.38)$ & $0.0072(7.20)$ & $0.07(-0.17,0.38)$ & $0.0071(7.30)$ \\
Mar & $0.30(0.16,0.51)$ & $0.0076(6.16)$ & $0.12(-0.11,0.45)$ & $0.0075(7.43)$ \\
Apr & $0.37(0.23,0.60)$ & $0.0082(5.89)$ & $0.12(-0.13,0.42)$ & $0.0083(8.64)$ \\
May & $0.40(0.25,0.64)$ & $0.0088(5.76)$ & $0.13(-0.01,0.46)$ & $0.0086(7.47)$ \\
Jun & $0.40(0.25,0.68)$ & $0.0089(5.70)$ & $0.27(0.10,0.49)$ & $0.0094(9.27)$ \\
Jul & $0.40(0.27,0.62)$ & $0.0090(5.70)$ & $0.30(0.13,0.53)$ & $0.0090(6.90)$ \\
Aug & $0.46(0.33,0.68)$ & $0.0090(4.94)$ & $0.28(0.08,0.59)$ & $0.0090(6.47)$ \\
Sep & $0.46(0.31,0.70)$ & $0.0096(5.41)$ & $0.22(-0.02,0.54)$ & $0.0093(6.80)$ \\
Oct & $0.20(0.25,0.64)$ & $0.0093(5.77)$ & $0.27(0.02,0.60)$ & $0.0089(6.91)$ \\
Nov & $0.24(0.11,0.42)$ & $0.0083(7.38)$ & $0.13(-0.16,0.54)$ & $0.0083(5.62)$ \\
Dec & $0.12(-0.02,0.31)$ & $0.0080(8.42)$ & & $0.0080(6.31)$ \\
\hline
\end{tabular}

rejected in eight of the months, and long memory patterns are only detected for July, August, September, and November. Nevertheless, the time trend coefficients are once more statistically significant in all cases, with values close to those given for the whole sample period (1884-2018).

These results are in line with other work conducted on sea surface temperature in the Mediterranean zone (see Pastor et al. 2019). They conclude that there is a consistent warming trend for the Mediterranean Sea in the period 1982-2016, finding different linear trends for seasons and months. Alexander et al. (2018) conclude that the warming trend projected in their research is positive (from $0.05^{\circ}$ to $0.5^{\circ} \mathrm{C} \mathrm{decade}{ }^{-1}$ ) and is generally higher in summer than in winter. Our findings are also consistent with many other studies, including Friedland and Hare (2007), Chollett et al. (2012), López García and Belmonte (2011), Shaltout and Omstedt (2014), Thomas et al. (2017) and others.

\section{Conclusions}

In this article we have examined the global monthly sea surface temperatures using a reconstructed dataset that goes back to 1884 . We use fractional integration techniques to investigate issues such as the degree of persistence in the data, the seasonality, and the presence of time trends. This specification is more general than other standard methods and includes the classical stationarity $I(0)$ and nonstationarity $I(1)$ as particular cases of interest. Our results indicate first that seasonality is a very relevant issue in the data, and, after testing for seasonal unit roots, the results provide strong evidence in favor of this hypothesis. Removing the seasonal component, throughout seasonal differentiation, the data are still very persistent and significant trends are observed across different sample periods. We provide evidence that the temperatures have increased between $0.07^{\circ}$ and $0.11^{\circ} \mathrm{C}$ during the last 100 years.

Acknowledgments. Professor Luis A. Gil-Alana gratefully acknowledges financial support from the Ministerio de Economía y Competitividad (ECO2017-85503-R). Comments from the editor and two anonymous reviewers are gratefully acknowledged.

\section{REFERENCES}

Alexander, M. A., J. D. Scott, K. D. Friedland, K. E. Mills, J. A. Nye, A. J. Pershing, and A. C. Thomas, 2018: Projected sea surface temperatures over the 21st century: Changes in the mean, variability and extremes for large marine ecosystem regions of northern oceans. Elementa, 6, 9, http://doi.org/ 10.1525/elementa.191.

Alvarez-Ramirez, J., J. Alvarez, L. Dagdug, E. Rodriguez, and J. C. Echeverria, 2008: Long-term memory dynamics of continental and oceanic monthly temperatures in the recent 125 years. Physica A, 387, 3629-3640, https://doi.org/ 10.1016/j.physa.2008.02.051.

Anderegg, W. R. L., J. W. Prall, J. Harold, and S. H. Schneider, 2010: Expert credibility in climate change. Proc. Natl. Acad. Sci. USA, 107, 12 107-12 109, https://doi.org/10.1073/ pnas.1003187107.

Banzon, V., T. M. Smith, T. M. Chin, C. Liu, and W. Hankins, 2016: A long-term record of blended satellite and in situ sea-surface temperature for climate monitoring, modeling and environmental studies. Earth Syst. Sci. Data, 8, 165-176, https:// doi.org/10.5194/essd-8-165-2016.

Beaulieu, J. J., and J. A. Miron, 1993: Seasonal unit roots in aggregate U.S. data. J. Econom., 55, 305-328, https://doi.org/ 10.1016/0304-4076(93)90018-Z.

Beckage, B., and Coauthors, 2018: Linking models of human behaviour and climate alters projected climate change. Nat. Climate Change, 8, 79-84, https://doi.org/10.1038/s41558017-0031-7.

Bloomfield, P., 1973: An exponential model in the spectrum of a scalar time series. Biometrika, 60, 217-226, https://doi.org/ 10.1093/biomet/60.2.217.

1992: Trends in global temperatures. Climatic Change, 21, 1-16, https://doi.org/10.1007/BF00143250. 
Breaker, L. C., 2019: Long-range persistence in sea surface temperature off the coast of central California. J. Ocean Climate, 9, https://doi.org/10.1177/1759313118791113.

Bunde, A., 2017: Long-term memory in climate: Detection, extreme events and significance of trends. Nonlinear and Stochastic Climate Dynamics, C. L. E. Franzke and T. O'Kane, Eds., Cambridge University Press, 318-339, https://doi.org/ 10.1017/9781316339251.012.

— significant is West Antarctic warming? Nat. Geosci., 7, 246247, https://doi.org/10.1038/ngeo2126.

Cane, M. A., A. C. Clement, A. Kaplan, Y. Kushnir, D. Pozdnyakov, R. Seager, S. E. Zebiak, and R. Murtugudde, 1997: Twentiethcentury sea surface temperature trends. Science, 275, 957-960, https://doi.org/10.1126/science.275.5302.957.

Chollett, I., F. E. Müller-Karger, S. F. Heron, W. Skirving, and P. J. Mumby, 2012: Seasonal and spatial heterogeneity of recent sea surface temperature trends in the Caribbean Sea and southeast Gulf of Mexico. Mar. Pollut. Bull., 64, 956-965, https://doi.org/10.1016/j.marpolbul.2012.02.016.

Cuestas, J. C., and L. A. Gil-Alana, 2016: A non-linear approach with long range dependence based on Chebyshev polynomials. Stud. Nonlinear Dyn. Econom., 20, 57-94, https://doi.org/ 10.1515/snde-2014-0005.

Dahlhaus, R., 1989: Efficient parameter estimation for self-similar processes. Ann. Stat., 17, 1749-1766, https://doi.org/10.1214/ aos/1176347393.

Deng, Q., D. Nian, and Z. Fu, 2018: The impact of inter-annual variability of annual cycle on long-term persistence of surface air temperature in long historical records. Climate Dyn., 50, 1091-1100, https://doi.org/10.1007/s00382-017-3662-5.

Deser, C., A. S. Phillips, and M. A. Alexander, 2010: Twentieth century tropical sea surface temperature trends revisited. Geophys. Res. Lett., 37, L10701, https://doi.org/10.1029/ 2010 GL043321.

Dickey, D. A., D. P. Hasza, and W. A. Fuller, 1984: Testing for unit roots in seasonal time series. J. Amer. Stat. Assoc., 79, 355-367, https://doi.org/10.1080/01621459.1984.10478057.

Eichner, J. F., E. Koscielny-Bunde, A. Bunde, S. Havlin, and H. J. Schellnhuber, 2003: Power-law persistence and trends in the atmosphere: A detailed study of long temperature records. Phys. Rev., 68E, 046133, https://doi.org/10.1103/ PhysRevE.68.046133.

Fatichi, S., S. M. Barbosa, E. Caporali, and M. E. Silva, 2009: Deterministic versus stochastic trends: Detection and challenges. J. Geophys. Res., 114, D18121, https://doi.org/ 10.1029/2009JD011960.

Folland C. K., O. Boucher, A. Colman and D. E. Parker, 2018: Causes of irregularities in trends of global mean surface temperature since the late 19 th century. Sci. $A d v ., 4$, eaao5297, https://doi.org/10.1126/sciadv.aao5297.

Franzke, C., 2010: Long-range dependence and climate noise characteristics of Antarctic temperature data. J. Climate, 23, 6074-6081, https://doi.org/10.1175/2010JCLI3654.1.

_ $2012 \mathrm{a}$ : On the statistical significance of surface air temperature trends in the Eurasian Arctic region. Geophys. Res. Lett., 39, L23705, https://doi.org/10.1029/2012GL054244.

,2012b: Nonlinear trends, long-range dependence, and climate noise properties of surface temperature. J. Climate, 25, 41724183, https://doi.org/10.1175/JCLI-D-11-00293.1.

- 2013: A novel method to test for significant trends in extreme values in serially dependent time series. Geophys. Res. Lett., 40, 1391-1395, https://doi.org/10.1002/grl.50301.
Friedland, K. D., and J. A. Hare, 2007: Long-term trends and regime shifts in sea surface temperature on the continental shelf of the northeast United States. Cont. Shelf Res., 27, 2313-2328, https://doi.org/10.1016/j.csr.2007.06.001.

Ghil, M., and R. Vautard, 1991: Interdecadal oscillations and the warming trend in global temperature time series. Nature, $\mathbf{3 5 0}$, 324-327, https://doi.org/10.1038/350324a0.

Gil-Alana, L. A., 2003: Estimation of the degree of dependence in the temperatures in the Northern Hemisphere using semi-parametric techniques. J. Appl. Stat., 30, 1021-1031, https://doi.org/10.1080/0266476032000076146.

_ 2005: Statistical model for the temperatures in the Northern Hemisphere using fractional integration techniques. J. Climate, 18, 5357-5369, https://doi.org/10.1175/JCLI3543.1.

_ 2008a: Time trend estimation with breaks in temperature time series. Climatic Change, 89, 325-337, https://doi.org/ 10.1007/s10584-008-9407-z.

_ 2008b: Warming break trends and fractional integration in the northern, southern, and global temperature anomaly series. J. Atmos. Oceanic Technol., 25, 570-578, https://doi.org/ 10.1175/2007JTECHA1025.1.

_ 2015: Linear and segmented trends in sea surface temperature data. J. Appl. Stat., 42, 1531-1546, https://doi.org/10.1080/ 02664763.2014.1001328.

_ 2018: Maximum and minimum temperatures in the United States: Time trends and persistence. Atmos. Sci. Lett., 19, e810, https://doi.org/10.1002/asl.810.

— tegration in the UK and Japanese consumption and income. J. Appl. Econ., 16, 95-114, https://doi.org/10.1002/jae.597.

__, and L. Sauci, 2019: US temperatures: Time trends and persistence. Int. J. Climatol., 39, 5091-5103, https://doi.org/ 10.1002/joc.6128.

— O. Yaya, and A. F. Fagbamigbe, 2019: Time series analysis of quarterly rainfall and temperature (1900-2012) in subSaharan African countries. Theor. Appl. Climatol., 137, 6176, https://doi.org/10.1007/s00704-018-2583-5.

Goela, P. C., C. Cordeiro, S. Danchenko, J. Icely, S. Cristina, and A. Newton, 2016: Time series analysis of data for sea surface temperature and upwelling components from the southwest coast of Portugal. J. Mar. Syst., 163, 12-22, https://doi.org/ 10.1016/j.jmarsys.2016.06.002.

Granger, C. W. J., 1980: Long memory relationships and the aggregation of dynamic models. J. Econom., 14, 227-238, https:// doi.org/10.1016/0304-4076(80)90092-5.

_ 1981: Some properties of time series data and their use in econometric model specification. J. Econom., 16, 121-130, https://doi.org/10.1016/0304-4076(81)90079-8.

_ , and R. Joyeux, 1980: An introduction to long memory time series models and fractional differencing. J. Time Ser. Anal., 1, 15-39, https://doi.org/10.1111/j.1467-9892.1980.tb00297.x.

Hamilton, J. D., 1994: Time Series Analysis. Princeton University Press, $820 \mathrm{pp}$.

Hansen, J., and S. Lebedeff, 1988: Global surface air temperatures: Update through 1987. Geophys. Res. Lett., 15, 323-326, https:// doi.org/10.1029/GL015i004p00323.

_- R. Ruedy, M. Sato, and K. Lo, 2010: Global surface temperature change. Rev. Geophys., 48, RG4004, https://doi.org/ 10.1029/2010RG000345.

Hasselmann, K., 1993: Optimal fingerprints for the detection of time-dependent climate change. J. Climate, 6, 19571971, https://doi.org/10.1175/1520-0442(1993)006<1957: OFFTDO $>2.0 . \mathrm{CO} ; 2$. 
Hegerl, G. C., H. von Storch, K. Hasselmann, B. D. Santer, U. Cubasch, and P. D. Jones, 1996: Detecting greenhouse gas-induced climate change with an optimal fingerprint method. J. Climate, 9, 2281-2306, https://doi.org/10.1175/ 1520-0442(1996)009<2281:DGGICC > 2.0.CO;2.

— , K. Hasselmann, U. Cubasch, J. F. B. Mitchell, E. Roeckner, R. Voss, and J. Waskewitz, 1997: On multi-fingerprint detection and attribution of greenhouse gas and aerosol forced climatic change. Climate Dyn., 13, 613-634, https://doi.org/ 10.1007/s003820050186.

Hosking, J. R. M., 1981: Fractional differencing. Biometrika, 68, 165-176, https://doi.org/10.1093/biomet/68.1.165.

Hylleberg, S., 1986: Seasonality in Regression. Academic Press, $296 \mathrm{pp}$.

_ 476 pp.

—, R. F. Engle, C. W. J. Granger, and B. S. Yoo, 1990: Seasonal integration and cointegration. J. Econom., 44, 215-238, https:/ doi.org/10.1016/0304-4076(90)90080-D.

IPCC, 1995: Climate Change 1995: The Science of Climate Change. J. T. Houghton et al., Eds., Cambridge University Press, 572 pp.

Jones, P. D., and G. C. Hegerl, 1998: Comparisons of two methods of removing anthropogenically related variability from the near surface observational temperature field. J. Geophys. Res., 103, 13 777-13 786, https://doi.org/10.1029/98JD01144.

—_, and A. Moberg, 2003: Hemispheric and large-scale surface air temperature variations: An extensive revision and an update to 2001. J. Climate, 16, 206-223, https://doi.org/10.1175/15200442(2003)016<0206:HALSSA > 2.0.CO;2.

—_, and T. M. L. Wigley, 2010: Estimation of global temperature trends: What's important and what isn't. Climatic Change, 100, 59-69, https://doi.org/10.1007/s10584-010-9836-3.

Kaplan, A., M. A. Cane, Y. Kushnir, A. M. Clement, M. B. Blumenthal, and B. Rajagopalan, 1998: Analyses of global sea surface temperature 1856-1991. J. Geophys. Res., 103, $18567-$ 18589, https://doi.org/10.1029/97JC01736.

Kaufmann, R. K., and D. I. Stern, 2002: Cointegration analysis of hemispheric temperature relations. J. Geophys. Res., 107, 4012, https://doi.org/10.1029/2000JD000174.

King, A. D., R. Knutti, P. Uhe, D. M. Mitchell, S. C. Lewis, J. M. Arblaster, and N. Freychet, 2018: On the linearity of local and regional temperature changes from $1.5^{\circ} \mathrm{C}$ to $2^{\circ} \mathrm{C}$ of global warming. J. Climate, 31, 7495-7514, https://doi.org/10.1175/ JCLI-D-17-0649.1.

Koscielny-Bunde, E., A. Bunde, S. Havlin, H. E. Roman, Y. Goldreich, and H.-J. Schellnhuber, 1998: Indication of a universal persistence law governing atmospheric variability. Phys. Rev. Lett., 81, 729-732, https://doi.org/10.1103/ PhysRevLett.81.729.

Lennartz, S., and A. Bunde, 2009: Trend evaluation in records with long-term memory: Application to global warming. Geophys. Res. Lett., 36, L16706, https://doi.org/10.1029/ 2009 GL039516.

López García, M. J., and A. M. C. Belmonte, 2011: Recent trends of SST in the western Mediterranean basins from AVHRR Pathfinder data (1985-2007). Global Planet. Change, 78, 127-136, https://doi.org/10.1016/j.gloplacha.2011.06.001.

Ludescher, J., A. Bunde, C. L. Franzke, and H. J. Schellnhuber, 2016: Long-term persistence enhances uncertainty about anthropogenic warming of Antarctica. Climate Dyn., 46, 263271, https://doi.org/10.1007/s00382-015-2582-5.

Massah, M., and H. Kantz, 2016: Confidence intervals for time averages in the presence of long-range correlations, a case study on Earth surface temperature anomalies. Geophys. Res. Lett., 43, 9243-9249, https://doi.org/10.1002/2016GL069555.

Mills, T. C., 2004: Time series modelling of trends in Northern Hemispheric average temperature series. Energy Environ., 15, 743-753, https://doi.org/10.1260/0958305042886741.

— , 2006: Modelling current trends in Northern Hemisphere temperatures. Int. J. Climatol., 26, 867-884, https://doi.org/ 10.1002/joc. 1286 .

_ 2007: Time series modelling of two millennia of Northern Hemisphere temperatures: Long memory or shifting trends? J. Roy. Stat. Soc., 170A, 83-94, https://doi.org/10.1111/j.1467985X.2006.00443.x.

Minobe, S., and A. Maeda, 2005: A 1 degree SST dataset compiled from ICOADS from 1850 to 2002 and Northern Hemisphere frontal variability. Int. J. Climatol., 25, 881-894, https://doi.org/ 10.1002/joc. 1170 .

Moberg, A., D. M. Sonechkin, K. Holmgren, N. M. Datsenko, and W. Karlén, 2005: Highly variable Northern Hemisphere temperatures reconstructed from low- and high-resolution proxy data. Nature, 433, 613-617, https://doi.org/10.1038/nature03265.

Monetti, R. A., S. Havlin, and A. Bunde, 2003: Long-term persistence in the sea surface temperature fluctuations. Physica $A$, 320, 581-589, https://doi.org/10.1016/S0378-4371(02)01662-X.

Mudelsee, M., 2019: Trend analysis of climate time series: A review of methods. Earth Sci. Rev., 190, 310-322, https://doi.org/ 10.1016/j.earscirev.2018.12.005.

Nicholls, N., G. V. Gruza, J. Jouzel, T. R. Kart, L. A. Ogallo, and D. E. Parker, 1996: Observed climate variability and change. Climate Change 1995: The Science of Climate Change, J. T. Houghton et al., Eds., Cambridge University Press, 133-192.

North, G. R., and K.-Y. Kim, 1995: Detection of forced climate signals. Part II: Simulation results. J. Climate, 8, 409-417, https:// doi.org/10.1175/1520-0442(1995)008<0409:DOFCSP > 2.0.CO;2. - — - S. S. P. Shen, and J. W. Hardin, 1995: Detection of forced climate signals. Part I: Filter theory. J. Climate, 8, 401-408, https://doi.org/10.1175/1520-0442(1995)008<0401: DOFCSP $>2.0 . C O ; 2$.

Papalexiou, S. M., A. AghaKouchak, K. E. Trenberth, and E. Foufoula-Georgiou, 2018: Global, regional, and megacity trends in the highest temperature of the year: Diagnostics and evidence for accelerating trends. Earth's Future, 6, 71-79, https://doi.org/10.1002/2017EF000709.

Pastor, F., J. A. Valiente, and J. L. Palau, 2019: Sea surface temperature in the Mediterranean: Trends and spatial patterns (1982-2016). Meteorology and Climatology of the Mediterranean and Black Seas, Springer, 297-309.

Percival, D. B., J. E. Overland, and H. O. Mofjeld, 2001: Interpretation of North Pacific variability as a short- and longmemory process. J. Climate, 14, 4545-4559, https://doi.org/ 10.1175/1520-0442(2001)014<4545:IONPVA > 2.0.CO;2.

Poppick, A., E. J. Moyer, and M. L. Stein, 2017: Estimating trends in the global mean temperature record. Adv. Stat. Climatol. Meteor. Oceanogr., 3, 33-53, https://doi.org/10.5194/ascmo-333-2017.

Rajaratnam, B., J. Romano, M. Tsiang, and N. S. Diffenbaugh, 2015: Debunking the climate hiatus. Climatic Change, 133, 129-140, https://doi.org/10.1007/s10584-015-1495-y.

Rayner, N. A., D. E. Parker, E. B. Horton, C. K. Folland, L. V. Alexander, D. P. Rowell, E. C. Kent, and A. Kaplan, 2003: Global analyses of sea surface temperature, sea ice, and night marine air temperature since the late nineteenth century. J. Geophys. Res., 108, 4407, https://doi.org/ 10.1029/2002JD002670. 
P. Brohan, D. E. Parker, C. K. Folland, J. J. Kennedy, M. Vanicek, T. J. Ansell, and S. F. B. Tett, 2006: Improved analyses of changes and uncertainties in sea surface temperature measured in situ since the mid-nineteenth century: The HadSST2 data set. J. Climate, 19, 446-469, https://doi.org/10.1175/JCLI3637.1.

, and Coauthors, 2009: Evaluating climate variability and change from modern and historical SST observations. Proc. OceanObs'09: Sustained Ocean Observations and Information for Society, Venice, Italy, European Space Agency, 819-829.

Robinson, P. M., 1994: Efficient tests of nonstationary hypotheses. J. Amer. Stat. Assoc., 89, 1420-1437, https://doi.org/10.1080/ 01621459.1994 .10476881$.

Rybski, D., A. Bunde, S. Havlin, and H. von Storch, 2006: Long-term persistence in climate and the detection problem. Geophys. Res. Lett., 33, L06718, https://doi.org/10.1029/2005GL025591.

, - - and H. von Storch, 2008: Long-term memory in 1000-year simulated temperature records. J. Geophys. Res., 113, D02106, https://doi.org/10.1029/2007JD008568.

Santer, B. D., K. E. Taylor, T. M. L. Wigley, J. E. Penner, P. D. Jones, and U. Cubasch, 1995: Towards the detection and attribution of an anthropogenic effect on climate. Climate Dyn., 12, 77-100, https://doi.org/10.1007/BF00223722.

Schlesinger, M. E., and N. Ramankutty, 1994: An oscillation in the global climate system of period 65-70 years. Nature, 367, 723726, https://doi.org/10.1038/367723a0.

Shaltout, M., and A. Omstedt, 2014: Recent sea surface temperature trends and future scenarios for the Mediterranean Sea. Oceanologia, 56, 411-443, https://doi.org/10.5697/oc.56-3.411.
Smith, T. M., R. W. Reynolds, T. C. Peterson, and J. Lawrimore, 2008: Improvements to NOAA's historical merged landocean surface temperature analysis (1880-2006). J. Climate, 21, 2283-2293, https://doi.org/10.1175/2007JCLI2100.1.

Stern, D., and R. K. Kaufmann, 2000: Is there a global warming signal in hemispheric temperature series? Climatic Change, 47, 411-438, https://doi.org/10.1023/A:1005672231474.

Stramska, M., and J. Białogrodzka, 2015: Spatial and temporal variability of sea surface temperature in the Baltic Sea based on 32-years (1982-2013) of satellite data. Oceanologia, 57, 223-235, https://doi.org/10.1016/j.oceano.2015.04.004.

Thomas, A. C., and Coauthors, 2017: Seasonal trends and phenology shifts in sea surface temperature on the North American northeast shelf. Elementa, 5, 48, https://doi.org/10.1525/elementa.240.

Turkington, T., B. Timbal, and R. Rahmat, 2019: The impact of global warming on sea surface temperature based El NiñoSouthern Oscillation monitoring indices. Int. J. Climatol., 39, 1092-1103, https://doi.org/10.1002/joc.5864.

Yaya, O. S., and O. J. Akintande, 2018: Long-range dependence, nonlinear trend, and breaks in historical sea surface and land air surface global and regional temperature anomalies. Theor. Appl. Climatol., 137, 177-185, https://doi.org/10.1007/ s00704-018-2592-4.

Yuan, N., M. Ding, Y. Huang, Z. Fu, E. Xoplaki, and J. Luterbacher, 2015: On the long-term climate memory in the surface air temperature records over Antarctica: A nonnegligible factor for trend evaluation. J. Climate, 28, 5922 5934, https://doi.org/10.1175/JCLI-D-14-00733.1. 